\title{
Implementation of Circular Economy Elements in the Mining Regions
}

\author{
Alina Pinchuk ${ }^{1}$, Nataliia Tkalenko ${ }^{2}$, and Vyktoriia Marhasova ${ }^{3}$ \\ ${ }^{1}$ Chernihiv National University of Technology, Marketing Department, 14035 Chernihiv, Ukraine \\ ${ }^{2}$ Chernihiv National University of Technology, Accounting, Tax and Audit Department, 14035 \\ Chernihiv, Ukraine \\ ${ }^{3}$ Chernihiv National University of Technology, Public Administration and Business Management \\ Department, 14035 Chernihiv, Ukraine
}

\begin{abstract}
The article is devoted to the issue of waste management in the mining regions, as the problems of industrial waste or waste products will always be relevant in nowadays. The most experts focus on urbanization processes, on increasing the resources' requirements, which in turn will increase the needs of the population and environmental pollution. The processing of waste in the mining regions can be achieved through the use of elements of the circular economy, which will lead to the economic use of natural resources and the interaction of economic, environmental and social development. The building of Eco-Industrial Park using a sector-clustered approach to waste management is suggested in the conclusions. The EcoIndustrial Park will allow related industries to work in symbiosis, where secondary raw materials can be involved in recycling, remanufacturing, recovery, regeneration.
\end{abstract}

\section{Introduction}

The entire modern world economy is aimed at increasing competitiveness and achieving the goals of sustainable development on the background of the formation and implementation of the principles of Industry 4.0, which is inextricably linked with the digitalisation and use of the latest technologies in all economic, industrial, commercial and social processes.

The trends, principles and methods of Industry 4.0 are being implemented in different fields in different ways, taking into account the direction of the conference and focusing on the mining industry, it can be noted that the use of a wide range of technological accelerators of Industry 4.0 allows us to provide a new level of production efficiency and rational use of natural resources (energy efficiency) within the framework of the "3R principle" - reduce, reuse, recycle. [1] However, in the mining regions $3 \mathrm{R}$ principle can also be supplemented by the principle of "remanufacture" to obtain a new economic cycle or ultimately a new energy, raw material or new product, as well as ensuring minimum environmental pollution. 


\section{Material and Methods}

Today, much attention is being paid to the issue of rational use of production and consumption results under the conditions of depletion of natural resources and large-scale environmental pollution, which carries catastrophic threats to the Earth's future.

The UN World Report of 2015 "Prospects for the Development of the Population in the World" [2] experts analyzed that the population of our planet is rapidly increasing (to date, 7.4 billion, and already in $2050-9.7$ billion and in 2100 the population of the planet will be 11.2 billion people). An increase in the number of population leads to an increase in the consumption of natural resources. However, natural resources are tirelessly exhausting, and some of them will be fully exhausted over 50-100 years. This is due to the fact that the urbanized needs of people and the rapid intensification of the development of science and technology are oriented only on consumer interests (increase in production capacity and profit maximization, which will inevitably lead to an ecological crisis).

According to the scale of this issue, the United Nations has formulated the long-term goals of world sustainable development in the XXI century, namely: at the United Nations Conference in September 2015, the goals of sustainable development (CSR) for the period 2016-2030 were adopted, which set out 17 goals of sustainable development and 169 tasks to be carried out by all countries of the world by 2030. The 17 goals of sustainable development include the work of three balanced directions: economic, social and environmental. Figure 1 shows the goals of sustainable development.

However, achieving such a balance so that social, economic and environmental needs are very symbiotic, requires a colloquial link with all actors, namely, the state, business and science. Today, global environmental problems are aggravating, among them: biodiversity reduction and environmental pollution. In connection with them, a violation of the natural balance occurs, and the further development and prosperity of humanity is in question.

Considering Figure 1, we can argue that most goals are interconnected and mutually complementary. Achieving sustainable development can be provided for a synergistic solution to the goals presented.

Within the framework of the presented research, the 12th goal of sustainable development (responsible consumption and production) is most relevant. This goal is the result of the transition to a new economic model - circular $[4,5,6,7,8,9]$.

\section{Results and Discussion}

The concept of sustainable development and circular economy are very similar: both concepts are global in nature; they emphasize the importance of better integrating environmental and social aspects with economic progress; both concepts emphasize intra- and intergenerational obligations arising from environmental hazards; both signal the importance of increasing the participation of the authorities and the public.

The main differences appear to be the following: the motives for sustainable development are based on past common traditions. While the motives for circular economy are the observation that resources can be used in a more efficient way. Sustainable development aims to benefit the environment, the economy and society as a whole, while the main beneficiaries of a circular economy are economic entities using this system.

The application of the circular economy in the industry makes it possible to create new innovative ways of production, the possibility of reuse of goods and materials with less resource costs, as well as the efficient use and protection of natural resources shortages. Circular economy is the premise and driver of the fourth industrial revolution

Linear economic models ("take, make, waste"), which were laid down in previous revolutions, are not able to work efficiently today, but bear global environmental problems 
[10]. Therefore, the question arises as to the need for the transition to a new resource efficient, energy saving model of the economy - circular (the economy of a closed cycle). Which is built on the principle of "take, make, reuse" [11].

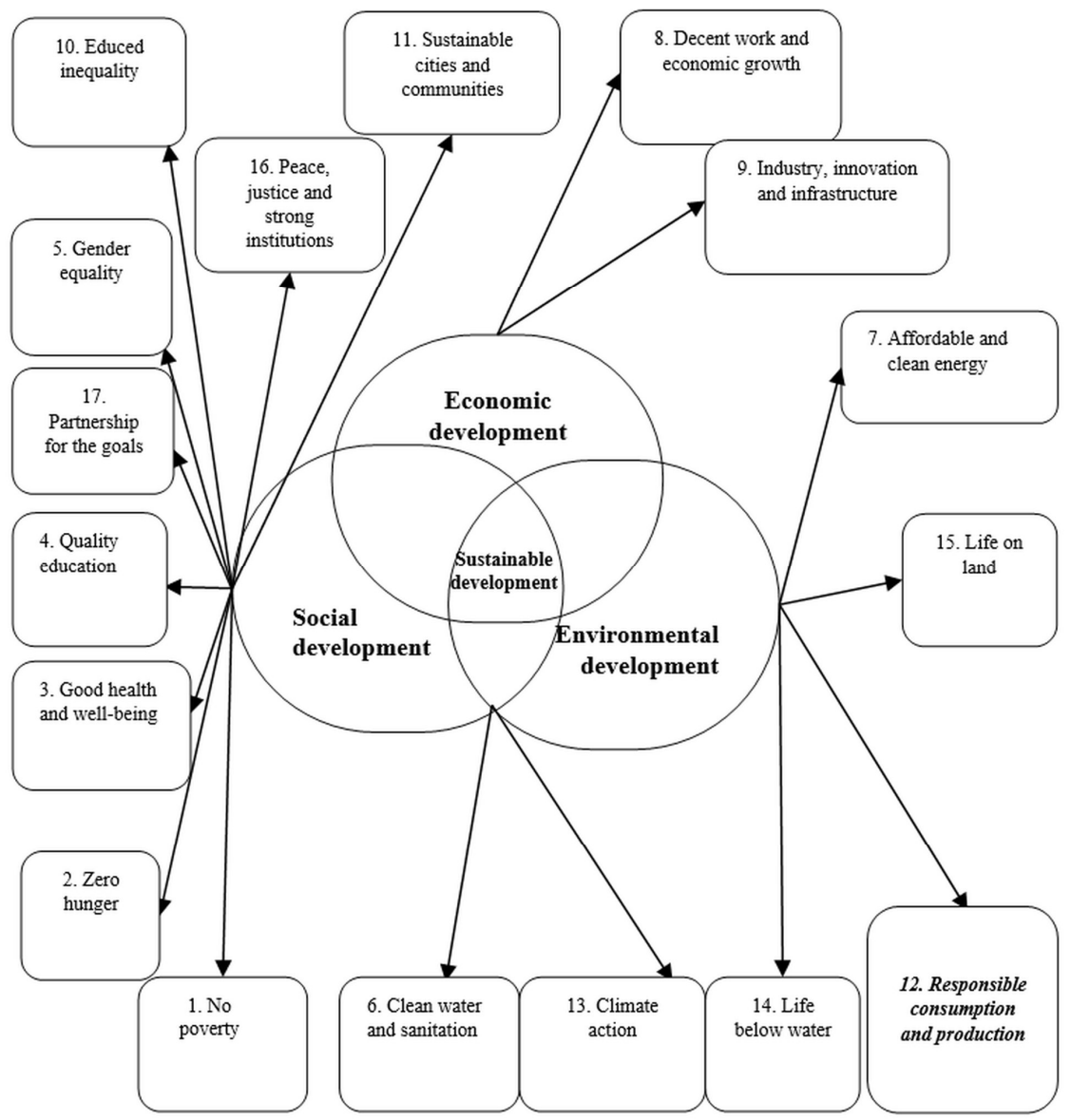

Fig.1. Sustainable Development Goals [3].

The mining industry has a major impact on the economy, but the extraction and processing of natural resources have catastrophically high waste levels, which leads to negative impacts on the part of the population and the environment. Mining produces a large amount of mineral raw materials, but only a small percentage is used for its intended purpose, while a significant part of the raw material is converted into a large amount of waste. As part of the solution to one of the goals of sustainable development, "responsible consumption and production", this issue becomes very relevant. The topic of our research is devoted to the application of elements of the circular economy in the mining industry, the application of which will minimize the energy needs of primary raw materials, reduce waste in all economic cycles using the principles of recycling, recovery, regeneration, remanufacturing $[12,13,14,15]$.

According to global trends, circular innovations and business models are beginning to emerge and flourish in an urbanized and environmentally-conscious environment. And the most important aspect of their appearance and development is the issue of financing.

It should be noted that in the scientific paper [16] it is noted that when applying the principle of reengineering, the product costs an average of $40-65 \%$ cheaper for the producer 
and $30-40 \%$ cheaper for the customer than the production and purchase of the new product, but the use of remanufacturing in many sectors of the industry are not fully used [17].

The largest amount of waste is in the ferrous and nonferrous metallurgy and coal industry. Waste in all the above mentioned industries can be used in many related industries, but for this it becomes necessary to develop a strategy for the exchange of raw materials for its processing between enterprises, to apply low-waste technologies and qualified personnel. In most post-Soviet countries, such technologies are almost non-existent, and for small mining companies, waste treatment is generally not economically feasible.

For example, the search for new deposits can have enormous financial costs and a lot of time, and as natural resources are depleted and exhausting, the amount of deposits is steadily declining. A large amount of waste is dust, slag, tails of enrichment, and many others. If they are not disposed of or recycled, then this will only lead to an increase in manmade deposits. Therefore, it is expedient to involve in the processing of waste from the raw material in the manmade field with the use of non-waste production, which in turn will reduce the load on the development of new deposits that occupy large areas of often fertile land, as well as maximize the use of all natural raw materials and minimize harm to the surrounding the environment.

However, to achieve full non-waste production in the mining industry is very difficult, and sometimes even impossible. At the same time, the processing of most waste can be done using the principle of industrial symbiosis, that is, any waste of one industry becomes a potential resource for another industry, where, after processing, the waste will turn into profit. This is quite a simple task for its solution, it is necessary that there is a correlation between the enterprise, but the result of the solution of this problem is resource conservation, energy conservation, low profitability and environmental protection from pollution of production and consumption.

In the conditions of development of a new technological structure, the transition from industrial parks to eco-industrial parks becomes necessary. Construction of an eco-industrial park will allow the use of accumulated waste from the production and processing of minerals for potential economic growth. For the application of elements of the circular economy in the mining industry, one option is the construction of an eco-industrial park within the technogenic field with the use of a sector-clustered approach to waste processing. That is, in the middle of the eco-industrial park there should be an industrial symbiosis, minimization of waste, simplified exchange of materials and resources between the various industries (within the circular economy, a closed cycle is desirable), re-engineering and recycling.

For example: waste products can be returned back to enrichment factories and mining enterprises to improve land reclamation (element remanufacturing). Waste in the form of slags is used for construction and road transport materials, in the chemical and pharmaceutical industries, and can also be used in glass manufacturing, which will allow for significant energy conservation (recycling).

The construction of an eco-industrial park requires large investments, a conceptual-new approach and an artificial mechanism of action, in which all contractors will be involved at both the regional and state levels.

Sustainable development of the mining industry requires the intensification of internal resources, the introduction of low-cost technologies in all business processes in order to minimize the cost of natural resources and introduce new technological innovations, recycling, etc., which will ultimately lead to significant economic and socio-environmental outcomes.

For most post-Soviet countries, the question of utilization of waste (mining industry and not only) and the very low level of re-use and disposal are extremely urgent. Applying the elements of the circular economy in different fields in the construction of sectoral-cluster- 
type eco-industrial parks provides the opportunity to increase the competitiveness of the region, increase resource efficiency, energy efficiency, and preserve the environment.

\section{Conclusions}

Summing up the above-mentioned, it can be stated that the main instrument for increasing environmental and economic indicators is the cooperation of heterogeneous enterprises united in the industrial symbiosis - the eco-industrial park; the key approach is the introduction of a circular economy in various fields that will achieve the 12th goal in the objectives of the World Sustainable Development, however, it should be noted that using this approach can be achieved the following 6 goals (6. Clean water and sanitation; 7. Affordable and clean energy 11. Sustainable cities and communities 13. Climate action 14. Life under water 15 . Life on land).

An important issue of the transition to a circular economy is to solve the problem of financing circular initiatives, since their non-profit period is much longer than traditional projects. This transition can be helped by government incentives through changes in taxation, government procurement, increased knowledge of the problem, creation of incentive complexes, and so on. Also, the widespread introduction of digital technologies should play a significant role in this.

The introduction of a circular economy can be implemented exclusively through Industry 4.0 due to the need to more effectively coordinate the flow of materials and information. The reason why the circular economy is not implemented today is the lack of information, and the digital economy is the "missing link" for its implementation. The main importance should be taken by the following technologies: cyber-physical systems, readers, automated market and logistics platforms, the Internet of things and blockchain.

Consequently, the application of the principles of the circular economy in the mining industry will lead to the economic, environmental and social benefits of the state, region, enterprises and a number of related enterprises that will operate in the structure of the ecoindustrial park, which is consistent with the concept of sustainable development.

\section{References}

1. P. Ghisellini, C. Cialani, S. Ulgiati, J. Clean. Prod., 114, 11-32 (2016)

2. UN Working Paper No. ESA/P/WP.241 World Population Prospects: The 2015 Revision, Key Findings and Advance Tables (UN, Department of Economic and Social Affairs, Washington, 2015).

3. Sustainable Development Goals and Integration. A Study Commissioned (German Council for Sustainable Development, Berlin, 2015)

4. M. Geissdoerfer, J. Clean. Prod., 143, 757-768 (2017)

5. J. Korhonen, A. Honkasalo, J. Seppala, Ecol. Econ., 143, 37-46 (2018)

6. M.H.A. Nasir, A. Genovese, Int. J. Prod. Econ., 183, $443-457$ (2017)

7. H. Nguyen, M. Stutchey, M. Zils, McKinsey Quarterly, 2, 125 (2014)

8. G. Pauli, Paradigm Publications, 10, 386 (2010)

9. E. Sundin, B. Bras, J. Clean. Prod., 13, 913-925 (2005)

10. O. Wyman, Supporting the Circular Economy Transition: The role of the finanvcial sector in Netherlands (Marsh \& MacLennan Companies, Amsterdam, 2017)

11. O. Pialot, D. Millet, J. Bisiaux, J. Clean. Prod., 141, 538-550 (2017) 
12. M.R. Johnson, I.P. McCarthy, Journal of Engineering and Technology Management, 34, 9-28 (2014)

13. A. Morrissey, Waste Management, 24:3, 297-308 (2004)

14. J. S. Thomas, J. P. Birat, Rev. Metall., 110, 3-16 (2013)

15. E. MacArthur, Green.Man. Int., 97, 110 (2012)

16. R. Giutini, K. Gaudette, Bus. Hor., 46:6, 41-48 (2003)

17. M. Matsumoto, S. Yang, K. Martinsen, Y. Kainuma, Int. J. P. E. M.G. T., 3;1, 129-142 (2016) 